cases between 10-15 years of operation in patients whose initial lesion was malignant. In gastrectomy for peptic ulcer disease the peak incidence occurred around the fourth decade after operation ${ }^{9}$.

Gastric stump cancer surgically treated has bad prognosis. Was observed lower five-year survival in patients with gastric stump cancer than those with primary gastric cancer ${ }^{10}$. The treatment of choice is surgical D2 resection of remaining stomach, plus lymphadenectomy including organs and other adjacent lymph nodes resection ${ }^{3}$.

To improve results is necessary early diagnose. Therefore, endoscopic surveillance should be considered ${ }^{10}$. However, there is no consensus in the literature on the screening of gastric stump cancer after gastrectomy. For some, the endoscopic surveillance program should start one year till at least ten years ${ }^{6}$. For others, gastrectomy for peptic ulcer disease should continue beyond ten years ${ }^{4,6,10}$. But everyone agrees on the need for early cancer detection and appropriate follow-up program ${ }^{10}$.

\section{REFERENCES}

1. CarrascoAL, BrescianiCJ,PerezRO,Zilberstein B, Cecconellol.Influência da invasão tumoral da linha de anastomose na sobrevivência de pacientes com câncer de coto gástrico. ABCD Arq. Bras. Cir. Dig. 2008; 21(2): 55-60.

2. Coelho LG, Maguinilk I, Zaterka S, Parente JM, Passos MC, Morais-Filho JP. 3rd Brazilian Consensus on Helicobacter pylori. Arq. Gastroenterol. 2013; 50(2): 81-96.

3. Hu X, Tian DY, Cao L, Yi Y. Progression and prognosis of gastric stump cancer. J. Surg. Oncol. 2009; 100: 472-6.

4. Lagergren J, Lindam A, Mason RM. Gastric stump cancer after distal gastrectomy for benign gastric ulcer in a population-based study. Int. J. Cancer. 2012; 131: E1048-52.

5. Monés J. Role of Helicobacter pylori in gastric cancer following partial gastrectomy forbenignulcer. Rev. Esp. Enferm. Dig.2005;97(11):767-77.

6. Namikawa $T$, Kitagawa $H$, Iwabu J, Okabayashi T, Kobayashi $M_{\text {, }}$ Hanazaki K. Tumors arising at previous anastomotic site may have poor prognosis in patients with gastric stump cancer following gastrectomy. J. Gastrointest. Surg. 2010; 14: 1923-30.

7. Safatle-Ribeiro AV, Ribeiro Jr. U, Sakai P, Iriya K, Ishioka S, GamaRodrigues J. Gastric stump mucosa: is there a risk for carcinoma? Arq Gastroenterol. 2001; 38(4): 227-31.

8. SitarzR,MaciejewskiR, PolkowskiWP, Offerhaus GJ.Gastroenterostoma afterBillrothantrectomyasapremalignantcondition.WorldJ.Gastroenterol. 2012; 18(25): 3201-6.

9. Tanigawa N, Nomura E, Lee SW, Kaminishi M, Sugiyama M, Aikou T Kitajima M, The Society for the Study of Postoperative Morbidity afte Gastrectomy. Current state of gastric stump carcinoma in Japan: based on the results of a nationwide survey. World J. Surg. 2010; 34: 1540-7.

10. Tokunaga M, Sano T, OhyamaS, Hiki N, Fukunaga T, Yamada K, Yamaguchi T. Clinicopathological characteristics and survival difference between gastric stump carcinoma and primary upper third gastric cancer. J. Gastrointest. Surg. 2013; 17: 313-8.

ABCDDV/1172

ABCD Arq Bras Cir Dig Letter to the Editor

2016;29(1):66

DOI: /10.1590/0102-6720201600010018

\title{
SURGICAL TREATMENT OF FISH IMPACTED IN THE UPPER ESOPHAGUS
}

Tratamento cirúrgico de peixe impactado no esôfago superior

Gustavo Rêgo COÊLHO, Silvio Melo TORRES,

Diego Costa de ALMEIDA, Laiza Marques MOREIRA, Thyago André Oliveira MENDES, Tiago Araújo MONTEIRO

From the Hospital Geral de Fortaleza, Fortaleza, Ceará, Brazil.

Correspondence:

Gustavo Rêgo Coêlho

E-mail:rcolleoni@uol.com.br
Financial source: none Conflicts of interest: none

Received for publication: 16/04/2014 Accepted for publication: 12/01/2016

I(c) Br Er This is an open-access artide distributed under the terms of the Creative Commons Attribution License. INTRODUCTION

$T$ he foreign body ingestion is common in emergency services. In most cases, it passes through the gastrointestinal tract spontaneously and does not cause any considerable damage. When the impaction occurs in the gastrointestinal tract, the most common level is the upper third of the esophagus. Approximately $10-20 \%$ of the cases requires endoscopic intervention and less than $1 \%$ needs some surgical procedure ${ }^{4,5}$. Usually, children from six months to six years old are more likely to that ${ }^{3}$. In adults, it is more common in individuals with psychiatric disorders, drug users, alcoholics or individuals that benefit from incident, as prisoners.

CASE REPORT

Male, 52, alcoholic and user of crack, previously healthy. Accidentally swallowed a Soy fish of approximately $15 \mathrm{~cm}$. It quickly progressed with hematemesis and respiratory failure before medical care._At the emergency room, it was observed respiratory arrest, being promptly intubated and laryngoscopy displayed the foreign body to the cervical esophagus. He was subjected to mechanical ventilation and remained hemodynamically stable. Endoscopy was performed soon after stabilization, but without success due to an intense inflammatory process and total occlusion of the esophageal lumen by the foreign body. Cervical and thoracic computed tomography showed the whole fish on cervical esophagus (Figure 1). The patient was submitted to surgical treatment with cervicotomy and esophagotomy, removal of the fish intact and primary synthesis of esophagus with Penrose drainage (Figure 2). He evolved without complications in surgical aspect, but with myoclonus and minimum response to the existing neurological deficit, resulting from a long period of pre-hospital cerebral hypoxia. 


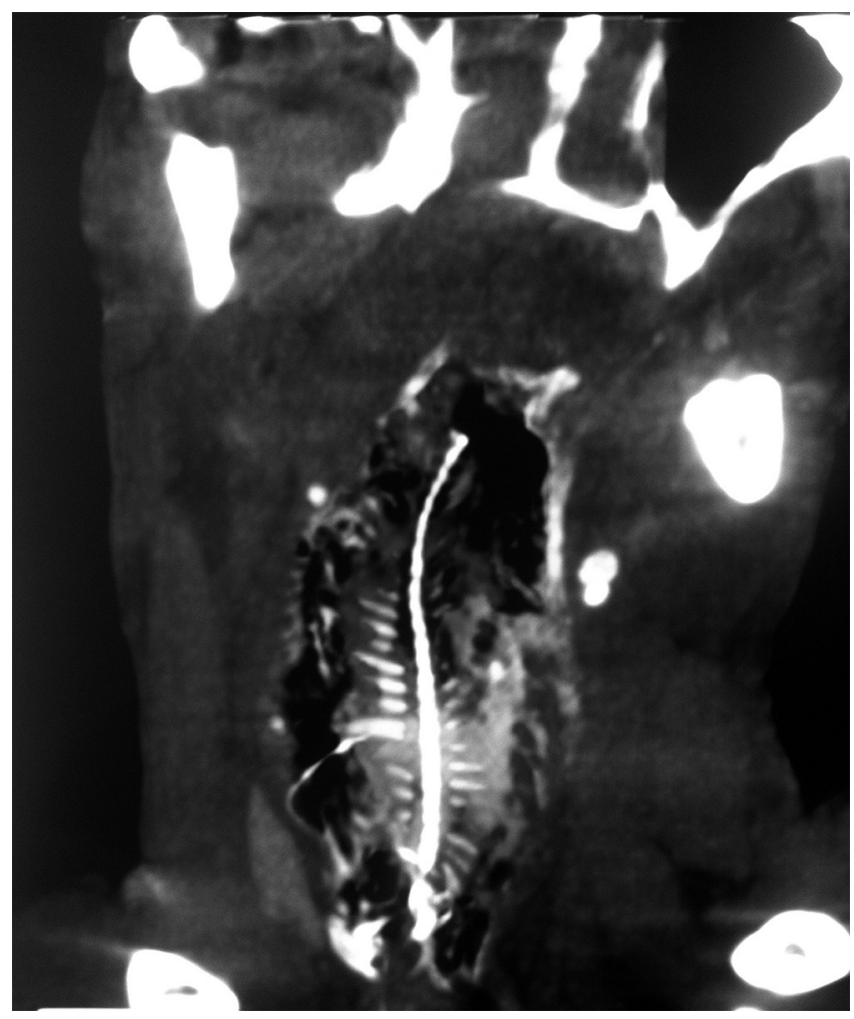

FIGURE1 - Coronal computed tomography of the neck clearly showing the fish impacted in cervical esophagus

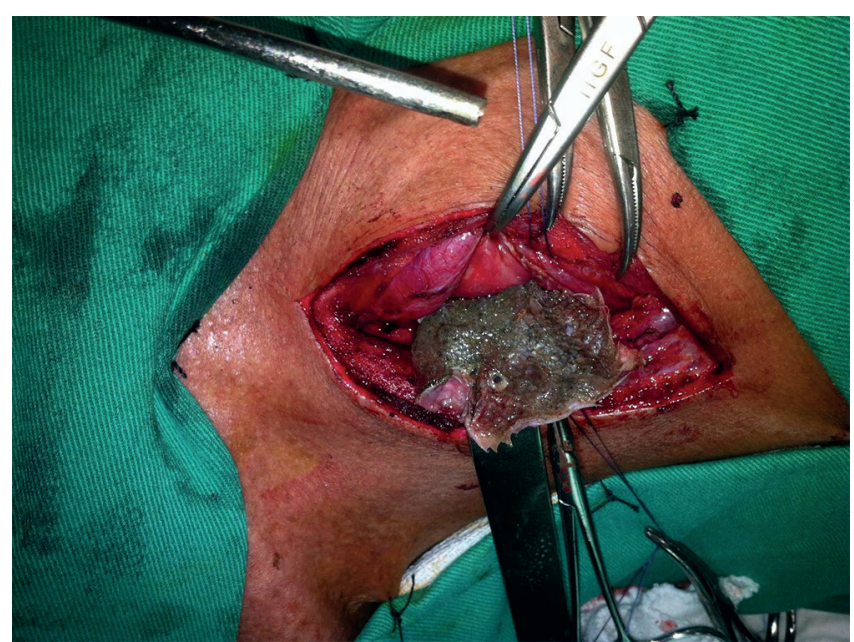

FIGURE 2 - Esophagotomy and removal of the intact fish

\section{DISCUSSION}

The greater part of foreign bodies (80\%) pass through the gastrointestinal tract without difficulties, but $20 \%$ can obstruct the lumen, requiring endoscopic or surgical removal ( $1 \%$ of cases). As the esophagus is a narrow portion of the gastrointestinal tract, 28-68\% objects are found in this region ${ }^{5}$. The symptoms depend on the location. Dysphagia, odynophagia and salivation suggest esophageal foreign body ${ }^{4}$. It can also present chest pain, cough, dyspnea, wheezing or stridor. In more severe cases, particularly in large or sharp foreign bodies, there may be intense pain, vomiting, refusal to eat, saliva ink with blood or shock ${ }^{1}$.

A medical review of database present several accidents involving foreign bodies ingestion, including food-bolus impactions, coins, fish bones, dental prostheses, chicken bones, iron slices, lighters, little metallic foreign bodies, toothbrushes, needles, and spoons ${ }^{5}$, but no reports involving the ingestion of whole fish. Impaction events with fish bones includes $12.6 \%$ of the accidents, the third highest in incidence ${ }^{5}$. As the majority of the bodies are radiopaque, the diagnosis can easily be done with plain radiography in posteroanterior and lateral projections. Endoscopy and contrasted study are needed in the case of radiotransparent objects. In all radiological exams it must be looked for signs of subcutaneous emphysema, which indicates drilling ${ }^{3}$. The treatment of choice is the endoscopic removal of the foreign body, which is successful with little or no complications for the patient ${ }^{2}$. The surgical treatment should be performed when endoscopic management is not possible to solve the problem, or if there is impairment of progression in the gastrointestinal tract or complications such as perforation, obstruction and bleeding ${ }^{2,3}$.

\section{REFERENCES}

1. Arana A, Hauser B, Hachimi-Idrissi $S$, Vandenplas Y. Management of ingested foreign bodies in childhood and review of the literature. Eur J Pediatr. 2001;160(8):468.

2. Brady PG. Esophageal foreign bodies. Gastroenterol Clin North Am 1991:20(4):691-701

3. Eisen GM, Baron TH, Dominitz JA, et al. Guideline for the management of ingested foreign bodies. Gastrointest Endosc 2002;55:802-6.

4. Hachimi-Idrissi S, Corne L, Vandenplas Y. Management of ingested foreign bodies in childhood: our experience and review of the literature. Eur J Emerg Med 1998;5:319-23.

5. Zhao-Shen Li, MD, Zhen-Xing Sun, MD, Duo-Wu Zou, MD, Guo-Ming $\mathrm{Xu}, \mathrm{MD}$, Ren-Pei Wu, MD,Zhuan Liao, MD. Endoscopic management of foreign bodies in the upper-GI tract: xperience with 1088 cases in China. Volume 64, No. 4: 2006 GASTROINTESTINAL ENDOSCOPY

ABCDDV/1173

ABCD Arq Bras Cir Dig Letter to the Editor 2016;29(1):67

DOI: /10.1590/0102-6720201600010019

\section{NEISSERIA MENINGITIDIS PERITONITIS SEROTYPE C: CASE REPORT}

Peritonite por Neisseria meningitidis sorotipo C: relato de caso

João Kleber de Almeida GENTILE', Maurice Youssef FRANCISS $^{1,2}$, Hamilton Ribeiro BRASIL ${ }^{1,2}$

From the ${ }^{1}$ Departamento de Cirurgia Geral da Irmandade da Santa Casa de Misericórdia de São Paulo, São Paulo, SP e ${ }^{2}$ Hospital Geral de Guarulhos ('Department of General Surgery of the Irmandade da Santa Casa de Misericórdia de São Paulo, São Paulo, SP and Guarulhos General Hospital, Guarulhos, SP), Brazil

Financial source: none Conflicts of interest: none

\section{Correspondence:}

João Kleber de Almeida Gentile E-mail:joaokleberg@gmail.com Received for publication: 04/02/2015 Accepted for publication: 15/12/2015

\section{INTRODUCTION}

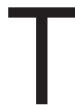
meningococcal disease manifestation as acute abdomen with meningococcal peritonitis is rare. Is reported primary peritonitis and bacteremia by Neisseria meningitidis serotype Coccurring in conjunction with the obstructive acute abdomen. 